\title{
Editorial
}

\section{Blá blá blá e Barbárie!}

\author{
Luciano Zanetti Pessôa Candiotto
}

Pelo fato deste número de AMBIENTES: Revista de Geografia e Ecologia Política ser composto majoritariamente pelo dossiê sobre neoextrativismo, que possui uma Apresentação elaborada pelos organizadores Fabiano Bringel e Klemens Laschefski, neste Editorial não tratarei diretamente do dossiê e de seus artigos. Apenas me limitarei a alguns comentários a respeito da atual conjuntura ambiental neste final de 2021.

Antes disso, quero apresentar o único material publicado neste número (Número 2 do Volume 3) que não faz parte do dossiê sobre neoextrativismo. Trata-se da resenha do livro Brasilien: Beiträge zur Wirtschafts - und Sozialgeographie aus über 50 Jahren Brasilien-Forschung, escrito pelo geógrafo alemão Gerd Kohlhepp. Na resenha “Brasilien: Virtudes e limitações de uma tradição de pesquisa", Marcelo Lopes de Souza apresenta e discute os elementos fundamentais da obra de Kohlhepp, um geógrafo com 50 anos de vivências e trabalhos pelo Brasil, com destaque para suas análises sobre a Amazônia. Como o livro não foi traduzido para o português, a leitura da resenha possibilita ter um contato com o cerne da obra. O livro corresponde a uma coletânea de 23 artigos e ensaios, escritos entre 1966 e 2017.

Nesses últimos meses, tem sido perceptível o crescimento da atenção da mídia por problemas e ações na área ambiental, sobretudo no Brasil. Consequentemente, isso leva 
a uma tendência de ampliação de informações e de conhecimentos por parte da sociedade sobre a problemática ou a "questão" ambiental, que é o principal mote desta Revista. Todavia, boa parte das informações não é positiva, pois as reportagens, opiniões e outras formas de comunicação adotadas, têm enfatizado um nefasto período de retrocessos das políticas e das ações para a preservação e conservação do ambiente, que estão, por sua vez, intimamente ligadas ao aumento da degradação ambiental. Por outro lado, as propagandas de empresas de diversos setores têm buscado utilizar o discurso de proteção ambiental, expandindo processos de greenwashing, ou seja, a busca de conquistar apoio e admiração da sociedade através de uma retórica ambientalmente correta. Energias renováveis (sobretudo a solar e eólica), meios de transporte elétricos e híbridos, embalagens e os mais diversos produtos "ecológicos" têm sido vendidos como a solução para a crise ambiental e como indicadores do caminho que estamos trilhando rumo a "sustentabilidade".

É possível afirmar que o evento que mais despertou o interesse da mídia nesse semestre tenha sido a COP-26 (Conferência do Clima organizada pela ONU) em Glasgow, Escócia, realizada no mês de novembro. Junto à COP-26, que reúne representantes de Estado de diversos países e de grandes corporações transnacionais, ocorreram eventos paralelos, organizados por ativistas, Organizações não-governamentais e por outros tipos de organizações sociais. Uma das principais figuras proeminentes desses grupos é a jovem ativista Greta Thumberg, que novamente afirmou que boa parte das pessoas estão cansadas de tanto blá blá blá, ou seja, de muito discurso, contrastado com poucas ações efetivas.

Após a COP-26, foi possível perceber que os avanços para frear a degradação ambiental, que não envolve somente a redução das emissões de carbono, foram extremamente tímidos. O chamado "Pacto de Glasgow" apenas referendou a intenção de se limitar o aumento da temperatura média do Planeta Terra em $1,5^{\circ} \mathrm{C}$, comparado a 1850, algo que por si só, já é uma tarefa difícil. Para tanto, as emissões globais de carbono teriam que ser reduzidas em 45\% até 2030 (comparadas com 2010), além da necessidade 
de redução da emissão de outros gases estufa. Contudo, quem irá monitorar isso? Aqueles países que não cumprirem com a meta serão punidos? Como? Na verdade, o referido Pacto não passa de uma vaga declaração de intenções, da mesma forma como tem ocorrido desde a Conferência de Estocolmo, em 1972. Ou seja, já são 50 anos de blá blá blá!

Ainda no contexto da COP-26, cabe destacar outras duas Declarações das quais o Brasil foi signatário. A "Declaração dos Líderes sobre Florestas", liderada pelo Reino Unido e assinada por 110 países, tocou em um dos graves problemas ambientais: o desmatamento. Apesar da promessa de se acabar com o desmatamento até 2030, através de investimentos vultuosos - em torno de bilhões de dólares - para promover a conservação e recuperação de florestas e outros ecossistemas terrestres, fica o questionamento sobre como esses recursos serão investidos e fiscalizados. Tem sido comum que governos de países ricos, historicamente beneficiados pela degradação ambiental, aportem recursos financeiros para ações ambientais. Contudo, quais os resultados efetivos desses investimentos? Que tipo de projetos e ações devem ser prioritários? Quem irá organizar a destinação dos recursos e o acompanhamento dos resultados? Apesar dessas dúvidas, vale destacar que a Declaração sobre Florestas reconheceu a importância de povos indígenas, quilombolas e comunidades tradicionais nos processos de redução do desmatamento e recuperação ecológica, e que foram incorporadas - pelo menos no documento - ações mais estruturais, como a necessidade de restruturação de políticas agrícolas e de redução da fome. No entanto, entre outras lacunas, a Declaração não previu penalidades para os países que descumprirem o acordo.

O Brasil também assinou, junto com outros 102 países, o "Compromisso Global de Metano", liderado pelos Estados Unidos e pela União Europeia. O principal objetivo é reduzir as emissões do gás metano em 30\% até 2030, mas as mesmas questões levantadas acima podem ser feitas neste caso. 
Resumindo, o contraste entre o discurso e Declarações com a realidade continua sendo enorme. Sem mudanças estruturais, seguiremos ouvindo muito blá blá blá e assistindo a consolidação da barbárie.

Ao fazer uma avaliação dos resultados da COP-26, o geógrafo Christian Zeller, da Universidade de Salzburg, Áustria, alertou para a complexidade do desafio que temos.

A meta de 1,5 grau requer uma reconstrução e desmontagem historicamente únicas de grandes partes de todo o aparato produtivo de nossas sociedades. Isso só é possível se rompermos com a compulsão de acumular mais e mais capital e maximizar o lucro e superar o modo de produção capitalista [...] em nossas demandas cotidianas.

Precisamos de uma sociedade que produza menos e de forma diferente, transporte menos, cuide mais das pessoas e da natureza, compartilhe riquezas de forma justa e tome decisões em conjunto'.

Enfim, sem mudanças estruturais nas formas de se produzir, transportar e consumir, continuaremos a ficar "enxugando gelo". Enquanto a cada dia surge um novo produto "ecológico", contraditoriamente (ou não!), a concentração da riqueza e as desigualdades têm se expandido de maneira avassaladora.

Novamente, a atuação do Brasil na COP-26 foi mais um capítulo da mentirosa retórica e da desastrosa gestão ambiental do Governo Bolsonaro. Apesar de assumir um novo compromisso de mitigar $50 \%$ de suas emissões de gases de efeito estufa (GEE) até 2030, os representantes do governo brasileiro não divulgaram os registros da maior taxa de desmatamento dos últimos 15 anos na COP-26. Esses dados foram divulgados dias depois do final da Conferência. Será que o governo brasileiro ainda não tinha essa informação? Ou será que simplesmente se esqueceram de divulgá-la na COP-26?

Esse panorama ambiental desanimador, me leva a recordar a fala de Marcelo Lopes de Souza, intitulada “A Ecologia-mundo na era do neoextrativismo”, no XIV Encontro Nacional de Pós-graduação em Geografia (ENANPEGE), realizado em outubro de 2021. Ao discutir como o sistema capitalista tem promovido uma apropriação privada

\footnotetext{
${ }^{1}$ Entrevista disponível no Blog do Pedlowski: <https://blogdopedlowski.com/2021/11/18/cop-26-nao-apenas-absurdomas-criminoso/>. Acesso em 27/11/2021.
} 
da natureza, gerando uma ampla rapina ambiental, injustiças ambientais, mas, também, lutas e conflitos como reação e contraposição, o professor Marcelo conclui que já estamos vivendo a barbárie, anunciada, há décadas, como uma das piores consequências do capitalismo.

Com base no avanço do neoextrativismo, sobretudo da mineração e do agronegócio no Brasil (e em outros países), unido a impunidade de desmatadores, garimpeiros, latifundiários e outros sujeitos que têm atuado de forma criminosa contra ambientes e pessoas, sobretudo os pobres e explorados, é possível afirmar que já estamos vivenciando a barbárie. A recente "corrida pelo ouro" no Rio Madeira (Amazonas), onde cerca de 300 balsas se deslocaram para realizar a dragagem ilegal de sedimentos em busca de ouro (Foto 1), é um exemplo marcante desta barbárie, moldada por ilegalidade, crimes e impunidade. A morosidade do Estado para barrar esse exemplo de rapina ambiental denota a gravidade do atual momento histórico.

E assim, a ofensiva neoextrativista continua, como mostram os artigos deste número. Estratégias variadas são utilizadas, nos planos jurídico, político, econômico e social. 
Foto 1 - Balsas se deslocando pelo Rio Madeira (AM), com destino à área de garimpo ilegal

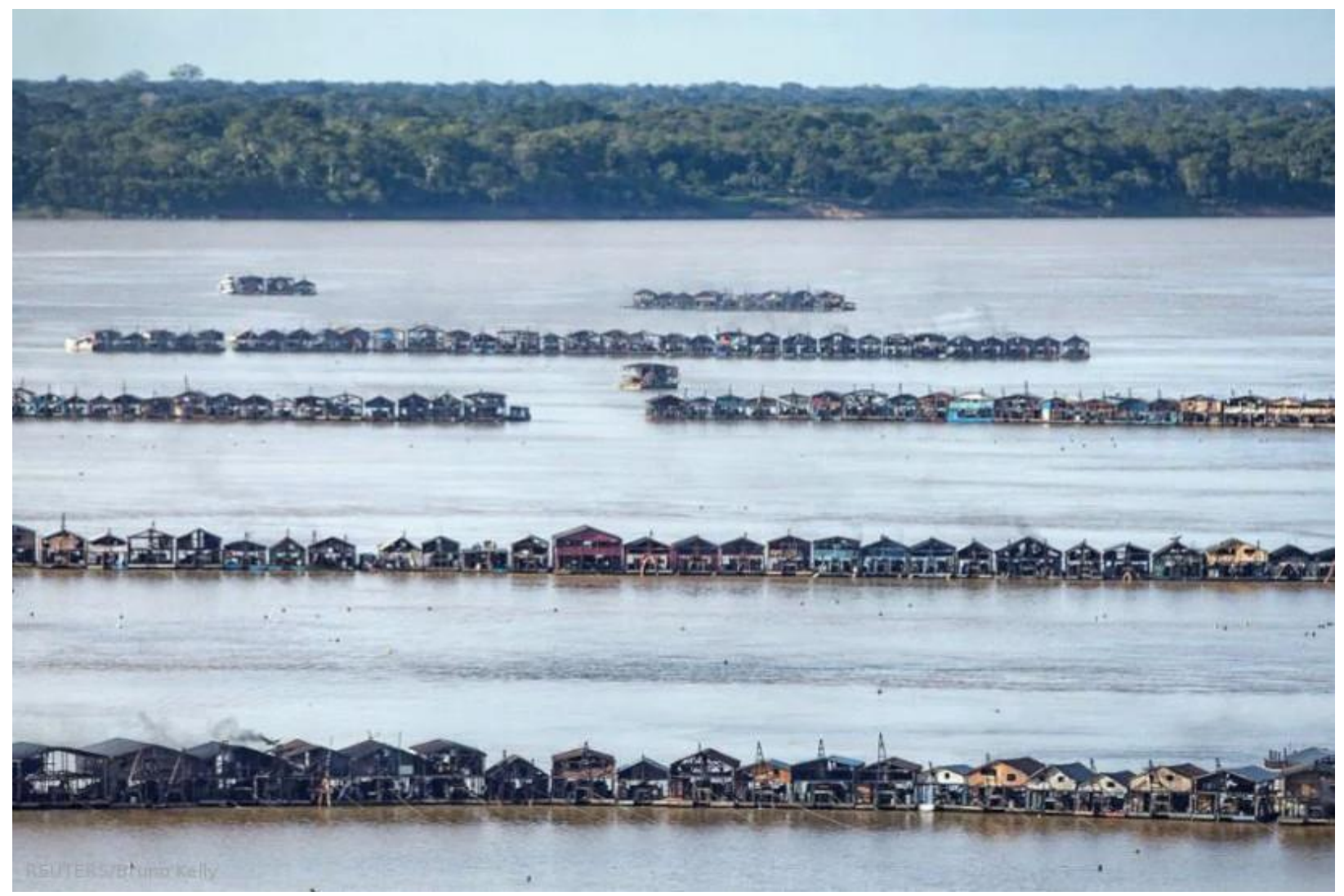

Fonte: Reportagem "O garimpo flutuante invade o rio Madeira", de 26/11/2021. Disponível em: <https://outraspalavras.net/outrasmidias/o-garimpo-flutuante-invade-o-rio-madeira/>. Acesso em 03/12/2021.

Apesar de a foto ilustrar um dos acontecimentos mais recentes, não faltam outros exemplos desse avanço do neoextrativismo e da estratégia neoliberal. Seja em áreas inóspitas, em fronteiras agrícolas, em assentamentos rurais, seja em pequenas, médias e grandes cidades brasileiras, a intolerância, a violência, os assassinatos, a perda de direitos e, por fim, a impunidade, denotam o atual estado de barbárie. Em outros países isso também tem acontecido, porém nosso cotidiano já é suficiente para ilustrar uma triste e preocupante realidade. 